\section{Non-reversible and wide ranging voice changes after treatment with danazol}

Side effects of drugs which result in conspicuous virilisation must be regarded as serious, especially if they do not reverse once the drugs are withdrawn. Danazol (Danol, Winthrop Laboratories) is licensed for use in endometriosis, benign breast disease, and menorrhagia. Early studies reported that androgenic side effects occurred infrequently, but more recent investigations show that acne occurs in between $21 \%$ and $27 \%$ of patients, hirsutism in $17-21 \%$, and deepening of the voice in $7-10 \% 0^{1-3}$ Early studies emphasised that in every case the voice change consisted solely of a lowering in pitch, which was reversed to normal once treatment was stopped.

We report a patient who developed a wider range of voice changes while taking danazol and which were still present 16 months after stopping the drug.

\section{Case report}

In June 1981 a 27 year old woman with severe endometriosis and primary infertility was prescribed danazol $600 \mathrm{mg}$ daily. A good clinical response was noted at gynaecological review in August and November. During that time further danazol was prescribed by the general practitioner. The only side effect that she attributed to treatment was a weight increase of $9 \mathrm{~kg}$.

In January 1982 the patient complained of voice changes. These had begun in September but she had not connected them to danazol and therefore had not mentioned them. She had attributed the changes to a throat infection but had not had soreness of the throat or otalgia. The general practitioner had prescribed two courses of antibiotics and also vitamin $C$ but with no response. She was referred for an otolaryngological opinion. Careful inquiry disclosed no obvious causative factors, and no abnormality was found on full examination, including indirect laryngoscopy. The surgeon advised the general practitioner a few days later that danazol might well be responsible but made no comment to this effect at the consultation.

The voice changes were initially of weakness, followed after a few weeks by persistent huskiness and occasional loss of pitch control, "squeaking" punctuating normal speech. The pitch of the voice when shouting was totally unpredictable, and weakness of the voice was exacerbated by prolonged talking. Danazol was discontinued at the end of January 1982, but 16 months later the voice changes were not improved. Further otolaryngological examination showed no abnormality. Results of a 24 hour urinary steroid profile and plasma concentrations of androstenedione, testosterone, and dihydroepiandrosterone sulphate were normal.

\section{Comment}

Danazol has been described as an impeded androgen with relatively greater myotrophic than androgenic action. Nevertheless, androgenic side effects are well recognised, ${ }^{12}$ voice change occurring in up to $10 \%$ of patients. ${ }^{3}$ The nature of the voice change reported previously was of a lowering in pitch, which reversed completely after danazol was stopped. Our patient continued to suffer not only this problem but also a loss of pitch control and voice weakness, and these changes remained 16 months after discontinuing treatment.

We do not know why our patient suffered such a wide range of adverse effects. She may have been particularly sensitive to the drug's androgenic and anabolic actions because her weight increased by $9 \mathrm{~kg}$. Although weight gain is a well recognised side effect (up to $85 \%$ of patients), changes of this magnitude are uncommon.

Failure to stop treatment when voice changes first occurred probably contributed to the wide range of changes and to their apparent permanency. The initial changes-weakness and huskinesshowever, have not been reported as side effects of danazol. This may explain why the general practitioner initially attributed these changes to a throat infection-and why the manufacturer's recommendation to stop treatment immediately if voice changes occur was not implemented. The final development of the voice changes had also not been associated with danazol, which may explain why the ENT surgeon, though subsequently surmising the correct diagnosis, failed to recognise danazol as the causative factor at the consultation.

The danazol dosage prescribed for this patient, $600 \mathrm{mg}$ daily, is often needed for control of symptoms due to endometriosis. Lower dosages of between 100 and $400 \mathrm{mg}$ daily may be effective in the treatment of dysfunctional uterine bleeding ${ }^{4}$ and benign breast disease ${ }^{5}$ and danazol is increasingly being advocated for these conditions. It is claimed that the incidence of side effects is reduced with lower dosages, ${ }^{12}$ and this may be true for headache and muscle cramps. ${ }^{3}$ Side effects such as hirsutism, weight gain, and voice change, however, may not be dose dependent and their severity seems to be related to the duration of treatment. ${ }^{3}$ Thus every physician prescribing this drug should alert all patients about the potentially virilising side effects and mention voice change specifically. We do not consider an incidence of voice change of up to $10 \%$ to be a negligible risk.

' Buttram VC, Belue JB, Reiter R. Interim report of a study of danazol for the treatment of endometriosis. Fertil Steril 1982;37:478-83.

2 Barbieri RL, Evans S, Kistner RW. Danazol in the treatment of endometriosis: analysis of 100 cases with a 4 year follow-up. Fertil Steril 1982; $37: 737-46$.

${ }^{3}$ Hosea SW, Santaella ML, Brown EJ, Berger M, Katusha K, Frank MM. Long term therapy of hereditary angioedema with danazol. Ann Intern Med $1980 ; 93: 809-12$.

4 Chimbira TH, Anderson ABM, Naish C, Cope E, Turnbull AC. Reduction of menstrual blood loss by danazol in unexplained menorrhagia: lack of effect of placebo. Br $\mathcal{F}$ Obstet Gynaecol 1980;87:1152-8.

${ }^{5}$ Mansel RE, Wisbey JR, Hughes LE. Controlled trial of the antigonadotrophin danazol in painful nodular benign breast disease. Lancet 1982 ; : 928-31.

(Accepted 2 fune 1983)

Infertility Clinic, Department of Obstetrics and Gynaecology, King's College Hospital, London SE5 8RX

P G WARDLE, MB, FRCS, registrar

M I WHITEHEAD, MB, MRCOG, senior lecturer and consultant obstetrician and gynaecologist

ENT Department, King's College Hospital, London SE5 8RX

R P MILLS, MB, FRCS, senior registrar

Correspondence to: $\mathrm{Mr} \mathrm{M}$ I Whitehead.

\section{Does diabetes affect employment prospects?}

High unemployment has been a problem in the west of Scotland for many years. In a climate of rising unemployment we sought to determine whether patients with diabetes experienced greater difficulty than the rest of the population in obtaining work.

\section{Patients, methods, and results}

A total of 500 patients ( 300 men and 200 women) of working age who were attending diabetic clinics at the Victoria Infirmary in Glasgow's south east district were given a questionnaire on employment. Replies were received from 244 men and 122 women, a total response rate of $73 \%$. One hundred and fifteen of the 244 men were insulin dependent, 81 were treated with oral hypoglycaemic agents, and the remainder were managed by diet alone. Seventy one of the 122 women used insulin injections, 27 were treated with oral drugs, and 24 by diet.

The table gives details of employment for the various categories. At the time of this survey, the registered unemployment figures for the south east district of Glasgow were: men 15049 of $74500(20.2 \%)$, women 6878 of $72400(9.5 \%)$ (total 21157 of $146900(14 \cdot 4 \%$ ) in the working age ranges). There was no difference in the distribution of socioeconomic groups between the diabetics and the local general population (figures available from authors); $156(64 \%)$ of men and $46(38 \%)$ of women possessed current ordinary driving licences.

\section{Comment}

We found no striking difference in the unemployment rate between diabetics and the general population. Indeed, men with diabetes appeared to fare better than men in general. The study sample was, however, necessarily small compared with the background population. Moreover, it would be better to compare the percentage of diabetics 
Results of questionnaire on employment experience of patients with diabetes

\begin{tabular}{|c|c|c|c|c|c|}
\hline & $\begin{array}{c}\text { Men } \\
(\mathrm{n}=244)\end{array}$ & $\begin{array}{l}\text { Women } \\
(\mathrm{n}=122)\end{array}$ & $\begin{array}{c}\text { Insulin } \\
\text { dependent } \\
(\mathrm{n}=186)\end{array}$ & $\begin{array}{l}\text { Non-insulin } \\
\text { dependent } \\
(\mathrm{n}=180)\end{array}$ & $\begin{array}{c}\text { Total } \\
(\mathrm{n}=366)\end{array}$ \\
\hline Mean age (years) & $52 \cdot 8$ & $44 \cdot 0$ & $40 \cdot 3$ & $53 \cdot 0$ & $48 \cdot 4$ \\
\hline $\begin{array}{l}\text { diabetes (years) } \\
\text { No (\%) employed }\end{array}$ & $\begin{array}{c}8 \cdot 2 \\
176(72)\end{array}$ & $\begin{array}{c}9 \cdot 2 \\
63(51)\end{array}$ & $\begin{array}{c}13 \cdot 0 \\
120(65)\end{array}$ & $\begin{array}{c}4 \cdot 5 \\
119^{(66)}\end{array}$ & $\begin{array}{c}8 \cdot 5 \\
239(65)\end{array}$ \\
\hline $\begin{array}{l}\text { unemployed } \\
\text { No }(\%) \text { ever refused }\end{array}$ & $35(14)$ & $9 \quad(7)$ & $25(13)$ & $19(11)$ & $44(12)$ \\
\hline $\begin{array}{l}\text { work because of } \\
\text { diabetes } \\
\text { No }\left({ }^{\prime}{ }_{11}\right) \text { ever made }\end{array}$ & $17 \quad(7)$ & $6 \quad(5)$ & $20(11)$ & $3(2)$ & $23(6)$ \\
\hline $\begin{array}{l}\text { No ( }{ }^{(1,)} \text { ever made } \\
\text { redundant because } \\
\text { of diabetes }\end{array}$ & $12(5)$ & $2(2)$ & $14(8)$ & & $14(4)$ \\
\hline $\begin{array}{l}\text { disabled } \\
\text { (No (0) of these } \\
\text { employed) }\end{array}$ & $\begin{array}{l}30(12) \\
(15(50))\end{array}$ & $\begin{array}{l}13(11) \\
(5(39))\end{array}$ & $\begin{array}{c}29(16) \\
(13(45))\end{array}$ & $\begin{array}{l}14(8) \\
(6(43))\end{array}$ & $\begin{array}{c}43(12) \\
(20(48))\end{array}$ \\
\hline
\end{tabular}

actually employed with the percentage of the general population actually employed, but figures for the latter are not readily available. Although there was no overall difference in the employment rate between the insulin dependent and non-insulin dependent patients, those taking insulin were more likely at some time to have been refused work or made redundant because of their diabetes. These differences may well relate simply to the greater cumulative employment experience of the insulin dependent patients because of the longer duration of their disorder. The insulin dependent patients were also more likely to be registered disabled, but about half of all patients on the disablement register were in employment.

It would appear that at a time when unemployment is rising and perhaps causing increased morbidity, the overall employment prospects for our patients with diabetes do not differ from those of the general population. This finding is similar to that of an earlier survey, which concluded that the vast majority of diabetics had little difficulty in finding a job. ${ }^{1}$

\section{' Jackson JGL. Employment survey. London: British Diabetic Association, 1958.}

(Accepted 7 fune 1983)

Victoria Infirmary, Glasgow G42 9TL

STEPHEN J HUTCHISON, MB, MRCP, medical registrar

COLIN M KESSON, MB, MRCP, consultant physician

STEFAN D SLATER, MD, FRCP, consultant physician

Correspondence to: Dr Colin M Kesson.

\section{Falciparum malaria resistant to chloroquine and fansidar: implications for prophylaxis}

Chloroquine resistant strains of Plasmodium falciparum have become established in east Africa since the first fully substantiated report of their existence in $1979 .^{1}$ As a result Fansidar (pyrimethamine $25 \mathrm{mg}$ and sulfadoxine $500 \mathrm{mg}$ ) has been recommended as routine antimalarial prophylaxis for this area. During the past year there have been several reports of falciparum malaria occurring in people taking Fansidar prophylaxis in east Africa together with reports of possible combined Fansidar and chloroquine resistance. ${ }^{2}$ We present a case of falciparum malaria resistant to both Fansidar and chloroquine with measurement of serum concentration of antimalarial agents before and during treatment and of in vitro chloroquine sensitivity.

\section{Case report}

A previously healthy 25 year old British academic spent 30 weeks in Tanzania from 20 February 1982, mainly in the region of Dar es Salaam. He had taken one tablet of Fansidar one week before his journey and continued this weekly throughout his stay. On 13 September he presented with fever, and a blood film confirmed the diagnosis of falciparum malaria. Over the next six days he received a total of $2 \cdot 2 \mathrm{~g}$ of chloroquine base but after 10 days heavy parasitaemia was still present and he took a further $1.65 \mathrm{~g}$ of chloroquine base and three tablets of Fansidar. He improved somewhat but returned to the UK on 4 October, and was immediately admitted to hospital. On admission his blood film showed moderate parasitaemia $(6690 / \mu \mathrm{l})$ and in the next 24 hours he received quinine, first intravenously then orally, and Fansidar. One week later scanty asexual parasites were still present and he took a second course of quinine followed by $2 \mathrm{~g}$ oxytetracycline daily for seven days. His blood was completely clear of asexual parasites on 27 October and he has remained well.

Chloroquine was measured by spectrofluorimetry, pyrimethamine by high performance quantitative thin layer chromatography, and sulfadoxine by reverse phase high pressure liquid chromatography on a C18 column with detection by absorption at $254 \mathrm{~nm}$. The in vitro sensitivity of the parasite to chloroquine was measured with the microtechnique of Rieckmann et al.

The results are shown in the table. The in vitro chloroquine concentration required for $99 \%$ inhibition of schizont maturation corrected for chloroquine present in the patient's blood on admission was $1952 \mathrm{nmol} / 1(629 \cdot 79 \mu \mathrm{g} / \mathrm{l})$ blood.

Serum concentrations of chloroquine, pyrimethamine, and sulfadoxine. At the end of the second day the patient received three tablets of Fansidar

\begin{tabular}{lrrrrrrrrr}
\hline \multicolumn{1}{c}{ Days after admission } & 0 & 1 & 2 & 3 & 8 & 9 & 17 & 24 & 31 \\
\hline Serum chloroquine $(\mathrm{nmol} / \mathrm{l})$ & 335 & & & & & & & & \\
Serum pyrimethamine $(\mathrm{nmol} / \mathrm{l})$ & 412 & & 412 & 2180 & 1164 & 568 & 384 & & 126 \\
Serum sulfadoxine $(\mathrm{nmol} / \mathrm{l})$ & 158 & 141 & 128 & 534 & 317 & 259 & 112 & 42 & 18 \\
\hline Asexual parasites $/ \mu \mathrm{l}$ & 6690 & 4840 & 15520 & 3180 & 320 & 350 & 100 & 0 & 0 \\
\hline
\end{tabular}

Conversion: SI to traditional units-Chloroquine: $1 \mathrm{nmol} / 1 \approx 0.323 \mu \mathrm{g} / 1$. Pyrimethamine: $1 \mathrm{nmol} / 1 \approx 0 \cdot 25 \mu \mathrm{g} / \mathrm{l}$. Sulfadoxine: $1 \mathrm{nmol} / 1 \approx 0 \cdot 310 \mu \mathrm{g} / 1$.

\section{Comment}

The serum chloroquine concentration of $335 \mathrm{nmol} / 1(108 \mu \mathrm{g} / \mathrm{l})$ on admission is adequate for treatment of sensitive strains of $P$ falciparum and the in vitro sensitivity of the parasite indicates a high level of resistance to chloroquine. Pyrimethamine sensitive strains of $P$ falciparum are eliminated by blood concentrations of less than $400 \mathrm{nmol} / 1(100 \mu \mathrm{g} / \mathrm{l})$ so parasitaemia in the presence of $412 \mathrm{nmol} / 1$ $(103 \mu \mathrm{g} / \mathrm{l})$ of pyrimethamine and of $158 \mathrm{nmol} / \mathrm{l}(49 \mu \mathrm{g} / \mathrm{l})$ of sulfadoxine indicates resistance to both agents - that is, to Fansidar.

It is increasingly difficult to advise on antimalarial prophylaxis in east Africa. There seems little to choose between chloroquine and Fansidar in normal doses as breakthrough infection has occurred with both and this case confirms that individual strains of $P$ falciparum may be resistant to both agents. After many reports of the RI pattern of chloroquine resistance of falciparum malaria acquired in east Africa a case of apparent high level resistance has been described, ${ }^{3}$ as a result of which the Centres for Disease Control have recommended the combination of chloroquine and Fansidar for prophylaxis in this area.

Chloroquine in a single dose of $600 \mathrm{mg}$ weekly (double the dose usually recommended) achieves serum concentrations which should be sufficient for complete suppression of RI chloroquine resistant strains of $P$ falciparum. ${ }^{4}$ Nevertheless, after about six weeks of this regimen a steady state is reached, with peak serum concentrations (about $1200 \mathrm{nmol} / 1(0.4 \mu \mathrm{g} / \mathrm{ml})$ ) which in a study of patients receiving daily chloroquine for rheumatoid disease were associated with symptoms including headache and mild confusion. ${ }^{5}$ If chloroquine is taken in a dose of $300 \mathrm{mg}$ twice weekly the peak serum concentration is unlikely to be within this range but antiparasitic activity is likely to be unaffected since chloroquine is concentrated in red cells.

In our opinion the most logical recommendation for antimalarial prophylaxis in non-immune persons in east Africa at the moment is chloroquine $300 \mathrm{mg}$ twice weekly, since this should provide a safe and effective defence against RI chloroquine resistant strains of $P$ falciparum. Until more is known about the determinants of toxicity this regimen should probably be followed for no more than one year. If, as seems likely, high level chloroquine resistance becomes established then Fansidar once weekly should be taken in addition to twice weekly chloroquine.

We thank Dr W H Wernsdorfer, World Health Organisation, Geneva, for his help and advice with the chloroquine in vitro sensitivity calculations Dr K A Fletcher, Liverpool School of Tropical Medicine, for determining the serum concentrations of chloroquine; and Dr H J Rogers, Guy's Hospital, London, for determining the serum concentrations of pyrimethamine and sulfadoxine.

${ }^{1}$ Campbell CC, Chin W, Collins WE, Teutsch SM, Moss DM. Chloroquineresistant Plasmodium falciparum from East Africa: Cultivation and drug sensitivity of the Tanzanian 1/CDC strain from an American tourist. Lancet 1979 ;ii:1151-4. 